\title{
A biblioteca escolar Enfermeira Zélia Maria Teixeira Cavalcante e a educação permanente em saúde: recurso didático-pedagógico
}

\author{
The school library Nurse Zélia Maria Teixeira Cavalcante and the permanent education in \\ health: didactic-pedagogical resource
}

\begin{abstract}
Bibliotecária - Documentalista da Universidade Estadual de Ciências da Saúde de Alagoas - Uncisal, Brasil. Pós-Graduanda em Biblioteconomia e Gestão de Bibliotecas Escolares pela Faculdade Venda Nova do Imigrante, campus Venda Nova do Imigrante, Brasil.

E-mail: gabicrispim@gmail.com

Maria Rejane Silva Barros
Pós-graduada em Biblioteconomia pela Faculdade Venda Nova do Imigrante, Brasil.
Bibliotecária - Documentalista
E-mail: $\underline{\text { rejaneufal @ gmail.com }}$
$\underline{\text { https://orcid.org/0000-0002-8812-6622 }}$

Francisca Rosaline Leite Mota Doutora em Ciência da Informação pela Universidade Federal de Minas Gerais - UFMG, Brasil. Professora Associada no curso de Biblioteconomia e do Pós-Graduação em Ciência da Informação da Universidade Federal de Alagoas - UFAL, Brasil Pesquisadora na Fundação de Amparo à Pesquisa do Estado de Alagoas - FAPEAL, Brasil.

E-mail: rosalinemota@gmail.com
\end{abstract}

\section{Resumo}

Analisa a Biblioteca Escolar Enfermeira Zélia Maria Teixeira Cavalcante enquanto recurso didático-pedagógico em sala de aula do Centro de Ensino Profissionalizante "Escola Técnica de Saúde Professora Valéria Hora (ETSAL)" da Universidade Estadual de Ciências da Saúde de Alagoas (UNCISAL). A Escola Valéria Hora oferta cursos nos níveis fundamental e médio (ensino técnico multiprofissional na saúde), através das instâncias gestoras da Política Nacional e Estadual de Educação para a Saúde em Alagoas. Inicialmente as atividades da escola atendiam as demandas da comunidade através de processo seletivo anual, cuja proposta pedagógica é feita por disciplina. Discussões sobre a Política de Educação em Saúde no estado; tornou a ETSAL integrante da Rede de Escolas Técnicas do Sistema Único de Saúde (RETSUS), criada pelo Ministério da Saúde. Sua participação na rede modificou a estrutura física e administrativa com a proposta formativa para alunos/trabalhadores do Sistema Único de Saúde. Os cursos passaram a ser ofertados nos 102 municípios alagoanos (descentralizados) e migraram da metodologia tradicional de ensino para metodologia ativa de aprendizagem com a prática de ensino por problematização e estudo de caso e estrutura organizada por currículo integrado. O objetivo do estudo é verificar as nuances que envolvem o setor administrativo e a biblioteca como um elemento importante para a construção da subjetividade do estudante. O percurso metodológico adotou como tipo de pesquisa o estudo de caso, tendo como instrumento para a coleta de dados a observação direta participante. Os resultados apontam para a inexistência de um diálogo efetivo entre os atores envolvidos nas práticas pedagógicas da escola de modo a inserir a biblioteca no currículo escolar. Além disto, foi possível observar que a atuação da biblioteca é mínima no projeto políticopedagógico, o acervo é inadequado, inexistem recursos tecnológicos e infraestrutura adequada, a frequência de usuários esporádica e, ainda, não possui bibliotecário. Conclui que no âmbito dos cursos descentralizados é necessário trabalhar também com a Biblioteca Virtual em Educação Permanente em Saúde e a inclusão de um referencial bibliográfico que remeta ao acervo físico, virtual ou misto para atender as demandas informacionais dos cursos na prática de ensino-aprendizagem em sala de aula. Por fim, considera que os materiais utilizados pelos instrutores e pelos alunos devem utilizar fontes de pesquisas científicas com critérios de qualidade nos campos de integração ensino-trabalho-comunidade, tornando a Biblioteca Escolar Enfermeira Zélia Maria Teixeira Cavalcante mais uma ferramenta pedagógica importante na aquisição e disseminação da informação.

Palavras-chave: Biblioteca escolar. Currículo escolar. Educação permanente. Estratégias de aprendizagem. 


\begin{abstract}
Analyzes School Library Nurse Zélia Maria Teixeira Cavalcante while didactic-pedagogical resource in the classroom of the professionalizing Education Center "Escola Técnica de Saúde Professora Valéria Hora (ETSAL)" of the State University of Health Sciences of Alagoas (UNCISAL). The Valéria Hora School offers courses levels at the elementary and high school levels (multipro fessional technical education in health), through the management bodies of the national and state health education policy in Alagoas. Initially the school's activities met the demands of the community through annual selection process, whose pedagogical proposal is made by subject. Discussions on the Health Education Policy in the state, made ETSAL a member of the Network of Technical Schools of the Unified Health System (RETSUS), created by the Ministry of Health. Its participation in the network modified the physical and administrative structure with the formative proposal for students / workers of the Unified Health System. The courses started to be offered in 102 municipalities in alagoanos (decentralized) and migrated from the traditional teaching methodology to learning active methodology the practice of teaching by problematization and case study and structure organized by an integrated curriculum. The objective of the study is to verify the nuances that involve the administrative sector and the library as an important element for the construction of the student's subjectivity. The methodological approach adopted as type of research the case study having as instrument for data collection direct participant observation. The results point to the lack of an effective dialogue between the actors involved in the school's pedagogical practices in order to insert the library into the school curriculum. In addition, it was possible to observe that the library's performance is minimal in the politicalpedagogical project, the collection is inadequate, there are no technological resources and adequate infrastructure, the frequency of sporadic users and, still, there is no librarian. It concludes that within the scope of decentralized courses be necessary to work alsowith the Virtual Library in Permanent Education in Health and the inclusion of a bibliographic referential that refers to the physical, virtual or mixed collection to meet the informational demands of the courses in the teaching-learning practice in classroom. Finally, considers that the materials used by instructors and students should use sources of scientific research with quality criteria in the fields of integration teaching-work-community integration, making the School Library Nurse Zélia Maria Teixeira Cavalcante one more pedagogical important tool in the acquisition and dissemination of information.
\end{abstract}

Keywords: School library. School curriculum. Permanent education. Learning strategies.

\title{
1. Introdução
}

A Constituição Federal do Brasil de 1988 (BRASIL, 1988) destaca em seu artigo 200, inciso III que compete ao Sistema Único de Saúde (SUS) "ordenar a formação de recursos humanos na área da saúde” e no inciso V que também é competência do SUS “incrementar em sua área de atuação, o desenvolvimento científico, tecnológico e a inovação”. Com base nestes preceitos constitucionais é que foram fundados no Brasil inúmeros cursos de formação em saúde, desde o nível fundamental até o nível superior.

Em Alagoas, duas estruturas públicas que atuaram na formação de nível médio para o setor da saúde até 1990, foram a Escola de Auxiliares de Enfermagem de Alagoas (EAEA) e o Centro Formador de Recursos Humanos para Saúde Doutor Waldir Arcoverde, ambos ligados ao Centro de Desenvolvimento de Recursos Humanos de Alagoas (CDRH).

A EAEA ofertava cursos para atender às demandas da comunidade através de processo seletivo anual, cuja proposta pedagógica era organizada por disciplinas (Auxiliar e Técnico de 
A biblioteca escolar Enfermeira Zélia Maria Teixeira Cavalcante e a educação permanente em saúde: recurso didático-pedagógico

Enfermagem). Já o CDRH atuava junto às demandas do Ministério da Saúde (MS) com o Projeto Larga Escala (1980), Programa de Profissionalização dos Trabalhadores da Área da Enfermagem (2000) e na formação dos trabalhadores de nível fundamental e médio, inseridos nos serviços de saúde e sem a devida formação.

Nos anos 2000 o Projeto de Profissionalização dos Trabalhadores da área de Enfermagem (PROFAE), em Alagoas, contou com a parceria do CDRH, com as duas estruturas responsáveis na formação de nível médio para o setor da saúde com dois componentes de financiamento "Formação" e "Estruturação da Escola”, do Ministério da Saúde:

[...] a importância de um "novo perfil" dos trabalhadores passa pela oferta de adequados processos de profissionalização e de educação permanente, bem como pelo aperfeiçoamento docente e renovação das políticas pedagógicas adotadas no ensino de profissionais de saúde. Visando superar o enfoque tradicional da educação profissional, baseado apenas na preparação do trabalhador para execução de um determinado conjunto de tarefas, e buscando conferir ao trabalhador das profissões técnicas da saúde o merecido lugar de destaque na qualidade da formação e desenvolvimento continuado, tornou-se necessário qualificar a formação pedagógica dos docentes $\mathrm{O}$ para esse âmbito do ensino. $\mathrm{O}$ contato, o debate e a reflexão sobre as relações entre educação e trabalho e entre ensino, serviço e gestão do SUS, de onde emanam efetivamente as necessidades educacionais, são necessários e devem ser estruturantes dos processos pedagógicos a adotar. Não por outro motivo, o Ministério da Saúde, já no primeiro ano da atual gestão, criou uma Secretaria de Gestão do Trabalho e da Educação na Saúde, que passa a abrigar o Projeto de profissionalização dos Trabalhadores da Área de Enfermagem (PROFAE) em seu Departamento de Gestão da Educação na Saúde. Dessa forma, o conjunto da Educação Profissional na Área da Saúde ganha, na estrutura de gestão ministerial, nome, lugar e tempo de reflexão, formulação e intervenção. (BRASIL, 2003, p. 8)

Para o fortalecimento das novas demandas do Ministério da Saúde em Alagoas com a Política de Educação em Saúde surgiu à necessidade de unificar as três unidades formativas, tornando a Escola de Auxiliares de Enfermagem de Alagoas, legalmente instituída através da (Lei Estadual n 6.351 de 09 de janeiro de 2003), como Escola Técnica de Saúde Professora Valéria Hora (ETSAL). Seu credenciamento, com a nova denominação e seus planos de cursos autorizados a funcionar, foi amparado na Resolução nº 073/2004 - CEE/AL, do Conselho Estadual de Educação de Alagoas e da Portaria $n^{\circ}$ 001/2005 - SEE/AL, em destaque a Resolução no 29/2016.

A ETSAL é Integrante da Rede de Escolas Técnicas do SUS (RET-SUS) como Polo de Educação Permanente em Saúde em Alagoas através da Portaria n. ${ }^{\circ}$ 198/GM/MS, em 13 de fevereiro de 2004, que instituiu a Política Nacional de Educação Permanente em Saúde (PNEPS) como estratégia para a formação e o desenvolvimento dos trabalhadores da saúde a partir dos princípios e diretrizes do SUS. A rede é uma estratégia governamental de articulação entre as Escolas Técnicas do Sistema Único de Saúde (ETSUS) para fortalecer a Educação 
Profissional em Saúde, criada pelo Ministério da Saúde, em parceria com o Conselho Nacional de Saúde (CNS), Conselhos Nacionais de Secretarias Municipais de Saúde (CONASEMS) e com a Organização Pan-Americana de Saúde/BRASIL (OPAS).

As ETSUS são instituições públicas (Federais, Estaduais e Municipais), distribuídas em todo o território nacional, instituídas no âmbito das Secretarias Estaduais e Municipais de Saúde ou em parceria com Secretarias Estaduais de Educação e de Ciência e Tecnologia. Em Alagoas a ETSAL é uma entidade estadual governamental que se tornou um Centro de Ensino Profissionalizante e Unidade Acadêmica da Universidade Estadual de Ciências da Saúde de Alagoas (UNCISAL), através da Lei Delegada n 47, de 10 de agosto de 2015. Destacamos que a referida Lei Delegada reestruturou o modelo de Gestão da Administração Pública Estadual do Poder Executivo em Alagoas.

Neste contexto, o novo panorama documental da escola ajudou a modificar suas decisões, tanto no âmbito administrativo quanto pedagógico, observando a oferta de cursos para a Formação Inicial e Continuada (FIC), Técnicos e Pós-Técnicos com vista a atender às demandas locais de formação técnica dos trabalhadores que atuam nos serviços de saúde inseridos nos 102 municípios alagoanos. Os cursos ofertados estão voltados para: Qualificação de formação inicial e continuada (Agente Comunitário de Saúde); Técnicos (Técnico em Vigilância à Saúde, Técnico em Hemoterapia, Técnico em Radiologia); Aperfeiçoamento (Qualificação de Agentes de Combate às Endemias), Atualização em sala de Vacina. A escola conta com a parceria dos gestores municipais, que disponibilizam a estrutura física (aulas teóricas), alimentação de alunos e a liberação dos seus trabalhadores de nível médio.

A viabilização e andamento dos cursos contam com fontes de financiamento do Ministério da Saúde por projetos e outras propostas decorrentes de pactuações de recursos da educação profissional, por meio de portarias ministeriais direcionadas às Comissões de Integração Ensino-Serviço (CIES) no estado, baseados na Portaria 1996/2007, que instituiu a Política Nacional de Educação Permanente em Saúde.

A Uncisal preocupada com a originalidade da oferta de cursos próprios inseriu no seu objetivo estratégico o Centro Valéria Hora no eixo, "Elevação da qualidade dos cursos técnicos e de graduação", com a meta de implantar um curso técnico próprio até 2017, fato este em desenvolvimento. A ETSAL pontua alguns itens necessários como: infraestrutura da escola, salas de aula, construção de novos laboratórios, reparos no antigo laboratório, aquisição de insumos, assim como previsão orçamentária para a execução de cursos a comunidade. $\mathrm{O}$ 
A biblioteca escolar Enfermeira Zélia Maria Teixeira Cavalcante e a educação permanente em saúde: recurso didático-pedagógico

diálogo tem como objetivo fortalecer as decisões administrativas e pedagógicas no propósito da continuidade na oferta de cursos para todo o sistema de saúde pública de Alagoas.

Contudo, não é possível pensar em elevação da qualidade de qualquer curso se não pensar na instituição Biblioteca Escolar (BE) ou Biblioteca Universitária (BU) como parte integrante de todo o processo de qualificação. Tomando por base está assertiva é que o presente artigo se insere e objetiva de forma geral: $\mathrm{O}$ objetivo do estudo é verificar as nuances que envolvem o setor administrativo e a biblioteca como um elemento importante para a construção da subjetividade do estudante. Para tanto, as seções foram estruturadas de forma a versar sobre: a BE como espaço de ensino aprendizagem dentro de uma perspectiva de educação permanente em saúde; as observações realizadas no decorrer da pesquisa e; as considerações depreendidas ao longo de todo o processo analítico e observacional do estudo de caso junto à Biblioteca Escolar Enfermeira Zélia Maria Teixeira Cavalcante.

\title{
2. A biblioteca escolar e a educação permanente em saúde
}

É possível encontrar no texto de Silva (2020) uma importante contribuição para a reflexão sobre o surgimento e evolução da BE no Brasil e os desafios contemporâneos no que se refere a efetivação da implantação da BE nacionalmente. Tendo origem que remontam aos tempos dos jesuítas, a BE precisa estar definitivamente imbicada nos processos educacionais da escola. Neste sentido, destaca que:

\begin{abstract}
A escola enquanto espaço de difusão do conhecimento, de formação de uma cultura letrada, precisa permitir o acesso a diferentes tipos de materiais informacionais, literatura nacional e internacional bem como, materiais de pesquisa. É no contexto de formação de uma sociedade leitora e para possibilitar o acesso a diferentes tipos de leitura que se coloca a biblioteca escolar. Tanto a escola como os agentes públicos devem reconhecer a importância da biblioteca escolar como instrumento primordial para a melhoria das condições de qualidade do ensino e para que os educandos possam alcançar outras formas de acesso e ampliação do saber [...]. (SILVA, 2020, p. 20).
\end{abstract}

Nesta mesma linha de visão, Côrte e Bandeira (2011, p. 8) destacam que a BE é "um espaço de estudo e construção do conhecimento, coopera com a dinâmica da escola, desperta o interesse intelectual, favorece o enriquecimento cultural e incentiva a formação do hábito da leitura". Deste modo, jamais pode legar a outras instituições, a exemplo das Bibliotecas Públicas, aquilo que é inerente a sua missão. Portanto, a BE necessita de preparação para "ser o suporte necessário para as atividades inerentes à proposta pedagógica da escola e aos diversos componentes curriculares, possibilitando ao estudante a ampliação do conhecimento por meio 
de pesquisas escolares, além de cumprir uma das missões mais importantes, a iniciação à leitura" (SILVA, 2020, p. 22).

A BE é objeto de grande preocupação por parte de bibliotecários e educadores que vislumbram esta importante instituição como o alicerce para a formação de leitores críticos e futuros cidadãos. Prova disto foi a constante luta empreendida pelo Conselho Federal de Biblioteconomia (CFB) para aprovar a Lei 12.244/10 que trata da Universalização da Biblioteca Escolar no território brasileiro e dispõe o que se segue:

Art. 1o As instituições de ensino públicas e privadas de todos os sistemas de ensino
do País contarão com bibliotecas, nos termos desta Lei. Art. 2o Para os fins desta Lei,
considera-se biblioteca escolar a coleção de livros, materiais videográficos e
documentos registrados em qualquer suporte destinados a consulta, pesquisa, estudo
ou leitura. Parágrafo único. Será obrigatório um acervo de livros na biblioteca de, no
mínimo, um título para cada aluno matriculado, cabendo ao respectivo sistema de
ensino determinar a ampliação deste acervo conforme sua realidade, bem como
divulgar orientações de guarda, preservação, organização e funcionamento das
bibliotecas escolares. Art. 3o Os sistemas de ensino do País deverão desenvolver
esforços progressivos para que a universalização das bibliotecas escolares, nos termos
previstos nesta Lei, seja efetivada num prazo máximo de dez anos, respeitada a
profissão de Bibliotecário, disciplinada pelas Leis nos 4.084, de 30 de junho de 1962,
e 9.674 , de 25 de junho de 1998 (BRASIL, 2010).

Em que pesem todos os esforços para a universalização da BE no país, Silva (2020) destaca, em pesquisa realizada junto a secretários municipais de educação, que é cada vez mais necessário e urgente: estabelecer prazos concretos para a implantação da BE em todas as escolas; ampliar recursos para efetivar tal implantação; contratar bibliotecários; formar um maior número de bibliotecários para atender a demanda de profissionais para gerenciar as $\mathrm{BE}$ implantadas; garantir a disponibilização de recursos para aquisição e diversificação dos acervos.

Vale ressaltar que a BE não pode se restringir a um espaço físico disponibilizado por uma instituição com o propósito de cumprir apenas exigências legais de órgãos normativos e reguladores. É necessário ir muito, além disto, e entender que a BE deve ser espaço pedagógico e democrático, capaz de desenvolver atividades no campo da pesquisa escolar e de outras ações educacionais e culturais que busquem a promoção do conhecimento e da cidadania.

Como bem destacam Moro et al. (2015, p. 51) não é possível melhorar o ensino sem fortalecer as bases educacionais da escola e "tal processo pode ser facilitado muito pelos serviços da biblioteca escolar, desde que esta seja estruturada adequadamente para dar cumprimento às suas responsabilidades técnicas, sociais e políticas no processo de ensinoaprendizagem e na formação cultural dos alunos". 
A biblioteca escolar Enfermeira Zélia Maria Teixeira Cavalcante e a educação permanente em saúde: recurso didático-pedagógico

É de fundamental importância que os atores que fazem parte do sistema educacional brasileiro, nas esferas federal, estadual e municipal, se conscientizem da necessidade efetiva do funcionamento das bibliotecas escolares, tendo em vista a importância das mesmas na melhoria do nível de aprendizagem dos alunos/as, especialmente quando falamos da realidade do ensino disponibilizado na rede pública. Para Andrade (2002, p. 15), a biblioteca é uma:

Instituição milenar que durante séculos garantiu a sobrevivência dos registros do conhecimento humano, tem agora seu potencial reconhecido como partícipe fundamental do complexo processo educacional. Pois, pode contribuir efetivamente para preparar crianças e jovens para viver no mundo contemporâneo, em que a informação e o conhecimento assumem destaque central.

A biblioteca tem caráter pedagógico no sentido de mediar à informação entre docente $\mathrm{e}$ discente no auxílio às pesquisas do conteúdo programático de sala de aula. Neste contexto é necessário que o bibliotecário escolar promova ações que possam envolver os docentes e discentes na busca por melhores níveis de aprendizagem. Neste sentido, é fundamental acrescentar as afirmações de Campello (2002, p. 22-23):

[...] a biblioteca escolar pode, sim, ser o local onde se forma o leitor crítico, aquele que seguirá vida afora buscando ampliar suas experiências existências através da leitura. [...] O bibliotecário e o professor mediadores da leitura devem ser, eles próprios, leitores críticos capazes de distinguir, no momento da seleção e da indicação de livros, a boa literatura infantil e juvenil daquela 'encomenda', com aparência moderna, engajada, mas totalmente circunstancial, cuja fórmula simplificada, abusivamente repetida, desprepara o leitor em formação para aceitação de outros textos, mais complexos, no futuro. [...] a escola que pretende investir na leitura como verdadeiramente cultural não pode ignorar a importância de uma biblioteca aberta, interativa, espaço livre para a expressão genuína da criança e do jovem.

A BE deve ser parte integrante do currículo escolar. Neste sentido, Mota (2004, p. 324) afirma que a BE "é uma ferramenta que pode ser utilizada para auxiliar no desenvolvimento do currículo escolar, permitindo o fomento à leitura e uma formação, por assim dizer, mais consolidada do indivíduo enquanto cidadão". No caso da BE no contexto da área da saúde, articular ensino e assistência, teoria e prática, ensino e comunidade. O bibliotecário possui papel de mediador, sendo partícipe no processo de ensino-aprendizagem do sujeito e, ainda, prover apoio aos educadores que atuam na formação dos discentes. Deste modo deve prevalecer o entendimento de que:

[...] a biblioteca escolar, assim como toda a diversidade de espaços tempos da escola, como elemento imprescindível para a constituição da subjetividade do estudante, não somente pela organização e disponibilização de acervos, mas também pela viabilização dos saberes fazeres que nele se fazem presentes e dele emergem, subsidiados pela sua existência, tomando por base a realidade da escola, seu projeto político-pedagógico e a cultura que fundamenta os modos de vida dos sujeitos constituintes da, e constituídos pela comunidade escolar (SILVA; MORAES, 2013, p. 2). 
A BE tem um papel fundamental auxiliando docentes e discentes no processo de ensino aprendizagem, conforme nos mostra Silva e Moraes (2013, p. 2):

[...] entende-se a biblioteca escolar, assim como toda a diversidade de espaços tempos
da escola, como elemento imprescindível para a constituição da subjetividade do
estudante, não somente pela organização e disponibilização de acervos, mas também
pela viabilização dos saberes fazeres que nele se fazem presentes e dele emergem,
subsidiados pela sua existência, tomando por base a realidade da escola, seu projeto
político-pedagógico e a cultura que fundamenta os modos de vida dos sujeitos
constituintes da, e constituídos pela comunidade escolar.

No cenário da Educação Permanente em Saúde (EPS) temos, de acordo com Miccas e Batista (2014, p. 171) que:

O Sistema Único de Saúde (SUS), pela dimensão e amplitude que tem, aparece na arena dos processos educacionais de saúde como um lugar privilegiado para o ensino e a aprendizagem, especialmente os lugares de assistência à saúde. Educar "no" e "para o" trabalho é o pressuposto da proposta de educação permanente em saúde (EPS). Os lugares de produção de cuidado, visando integralidade, corresponsabilidade e resolutividade são, ao mesmo tempo, cenários de produção pedagógica, pois concentram, o encontro criativo entre trabalhadores e usuários.

Ainda em consonância com os autores supracitados a EPS deve ser estruturada de maneira que se configure como instrumental capaz de possibilitar alto nível de especialização dos profissionais no que se ao conhecimento da realidade local, ou seja, de seu campo de prática e atuação. E para a obtenção de tal conhecimento é necessário recorrer a uma constante formação, ou seja, a EPS propriamente dita, cenário em que a BE deve exercer papel preponderante. Os profissionais da área da saúde demandam uma constante atualização, sendo o processo de formação contínuo. Além de se especializarem para o exercício profissional, devem ser capazes de replicar os conhecimentos em prol das comunidades por eles assistidas.

Para atender a esta indiscutível demanda social e educativa é imprescindível que as instituições formadoras busquem capacitar da melhor forma possível os profissionais. No contexto da BE, acervo e infraestrutura física e tecnológica adequadas são fundamentais neste processo. Ademais a interação entre gestores, docentes e bibliotecários é, por vezes, decisiva para o sucesso do ensino-aprendizagem. A parceria entre estes profissionais é cada vez mais necessária e depende de uma grande conscientização de todos. Pois, só assim a comunidade escolar poderá vir a ter maiores oportunidades na obtenção de informações científicas com critérios de qualidade para atender as necessidades informacionais nos campos de integração ensino-trabalho-comunidade em que está ou será inserida. 
A biblioteca escolar Enfermeira Zélia Maria Teixeira Cavalcante e a educação permanente em saúde: recurso didático-pedagógico

\section{Metodologia}

O percurso metodológico adotou como tipo de pesquisa o estudo de caso que conforme Severino (2007, p. 21) é uma pesquisa que "se concentra no estudo de um caso particular, considerado representativo de casos análogos, por ele significativamente representativo". A unidade escolhida foi a Biblioteca Escolar Enfermeira Zélia Maria Teixeira Cavalcante por ser considerada representativa dos modelos de BE adotadas pelas Escolas Técnicas Federais, Municipais e Estaduais.

A pesquisa documental também subsidiou a coleta dos dados que usou como instrumento a observação direta intensiva que, de acordo com Marconi e Lakatos (2006, p. 193) possui vantagens como, entre outras coisas, a possibilidade de estudar uma gama variada de fenômenos, proporciona a coleta de dados sobre atitudes comportamentais típicas e a evidência de dados não contemplados por outros instrumentos de coleta de dados, a exemplo das entrevistas e questionário.

A observação direta intensiva foi realizada junto às dependências da Biblioteca Escolar Enfermeira Zélia Maria Teixeira Cavalcante no decorrer do primeiro e segundo semestre de 2019 e também buscou dados nos documentos institucionais como diagnóstico, Projeto Político Pedagógico da ETSAL, portarias, resoluções normativas, planos de cursos e materiais didáticos.

\section{Análise e discussão dos resultados}

A estrutura física da Biblioteca Escolar Enfermeira Zélia Maria Teixeira Cavalcante foi montada a partir da adesão do Programa de Profissionalização dos Trabalhadores da Área da Enfermagem (2000), componente de financiamento "Estruturação da Escola" com três projetos que versavam sobre informatização, biblioteca e capacitação. Para dar apoio ao desenvolvimento das atividades curriculares dos cursos ofertados entre os anos 2003 a 2009, a biblioteca trabalhou pedagogicamente com duas estruturas curriculares, sendo uma por Disciplinas e a outra por Currículo Integrado.

O Currículo por disciplina foi o primeiro estudo pedagógico de cursos iniciais para a comunidade. Os dados registrados nos "Cadernos de Visita" da biblioteca informam que entre os anos 2000 a 2007, cento e sessenta e nove (169) pessoas frequentaram a biblioteca para usufruírem dos serviços de empréstimo, renovação, devolução de materiais, acesso a sala de vídeo e de informática. 
Entre os anos 2007 a 2009 a biblioteca foi perdendo sua força, quanto à frequência de usuários, por causa da descentralização dos cursos nos municípios e a extinção de cursos próprios. Sua estrutura física foi reduzida, ficando um acervo subutilizado e isto resultou na desarticulação entre escola e biblioteca por 11 anos (2007 a 2018). Documentalmente não há registros de anos posteriores a 2007, causando lacuna documental, levando à questionamentos quanto ao grau de cooperação do bibliotecário, comunicação com os setores administrativos e pedagógicos.

A realidade vivenciada pelo corpo docente, discente, administrativo e a comunidade em geral, levantou questionamentos quanto à usabilidade da Biblioteca Escolar como a única no Estado de Alagoas com educação profissionalizante na modalidade de ensino técnico multiprofissional. Os usuários da Biblioteca Maria Zélia Teixeira Cavalcante, devido ao fato de, muitas vezes, não terem suas necessidades informacionais satisfeitas, recorriam à pesquisas na internet de modo individual e sem o auxílio de um bibliotecário que pudesse conduzir ao encontro com as melhores evidencias cientificas.

Em 2016, foi apresentado um Diagnóstico para a Direção Geral da Escola e Biblioteca Central da Uncisal, com objetivo de identificar os pontos fortes e fracos, compreender a natureza e as causas dos problemas ou desafios a serem enfrentados. O Diagnóstico oportunizou o estudo da Política de Desenvolvimento de Coleções que, de acordo com Maciel e Mendonça (2000, p. 16), é "uma atividade de planejamento, onde o reconhecimento da comunidade a ser servida e suas características culturais e informacionais oferecerão a base necessária e coerente para o estabelecimento de políticas de seleção [...]”.

Para a elaboração do referido diagnóstico foi realizado um estudo da comunidade baseado em dois tipos de ensino, cursos próprios e projetos do Ministério da Saúde, ambos com propostas pedagógicas diferenciadas. A seleção verificou se havia indicação de bibliografias e materiais especiais dos cursos oferecidos, o nível dos alunos e se havia algum aspecto pedagógico nos materiais didáticos utilizados. Todos esses elementos colaboraram para o entendimento de que a definição do acervo a ser adquirido deve levar em consideração a viabilidade de fontes de recursos preconizada em Portarias Ministeriais oriundas do PROFAPS e Recursos da Educação Permanente pactuadas em nível de Comissões de Integração EnsinoServiço (CIES) no estado.

A Formação do acervo da Biblioteca Escolar Enfermeira Zélia Maria Teixeira Cavalcante, foi regulamentada através da Resolução Nº 29/2016-CEE/AL do Conselho 
A biblioteca escolar Enfermeira Zélia Maria Teixeira Cavalcante e a educação permanente em saúde: recurso didático-pedagógico

Estadual de Educação de Alagoas. Normas para ofertas dos cursos e programas de Educação Profissional e Tecnológica, no Sistema Estadual de Ensino de Alagoas que determina, dimensão da coleção física do acervo:

\begin{abstract}
§ 9 - Da Biblioteca, Recursos Tecnológicos e Laboratórios.
I - acervo para biblioteca será composto por títulos de: literatura (universal, brasileira, alagoana), dicionários, enciclopédias, livros didáticos, livros técnico-científicos, livros artísticos, atlas, mapas, revistas e periódicos, tanto destinados aos alunos como aos docentes; II - acervo de áudio, vídeo e mídia eletrônica com exemplares de natureza educativa, artística e científica; III - o acervo da biblioteca deve dispor, no mínimo, de 05 (cinco) títulos para cada 20 (vinte) alunos por área do conhecimento da base nacional comum do ensino médio (quando ofertar a forma integrada) e dos componentes curriculares do(s) cursos de educação profissional técnica de nível médio ofertados na instituição, e, no mínimo, 01(um) exemplar por título para cada 100 (cem) alunos, distribuídos nas categorias enunciadas na alínea "f" deste inciso; IV - o acervo de áudio, vídeo e mídia deve dispor, no mínimo, de 05 (cinco) títulos por área do conhecimento da base nacional comum do ensino médio (quando ofertar a forma integrada) e dos componentes curriculares do(s) cursos de educação profissional técnica de nível médio ofertados na instituição (ALAGOAS, 2017).
\end{abstract}

A estrutura básica de acervo como está disposto acima é obrigatória. Contudo, em momentos anteriores o acervo da Biblioteca Escolar Enfermeira Zélia Maria Teixeira Cavalcante foi montado para atender a demanda de cursos próprios. É importante ter o entendimento de que a coleção deverá fortalecer a educação básica na formação de nível médio para o setor saúde em Alagoas, já que a escola possui a proposta de formar trabalhadores da saúde com qualidade técnica e científica na progressão ensino e serviço. Para tanto deve disponibilizar um acervo físico, virtual ou misto atualizado com conteúdos científicos capazes de auxiliar o corpo docente e discente nas pesquisas científicas para a produção de trabalhos dentro e fora da sala de aula. Só assim a biblioteca poderá ser vista como um recurso didáticopedagógico importante na produção do conhecimento e, consequente, melhoria da prática profissional em saúde.

Após a análise do diagnóstico buscamos entender a relação estabelecida entre a ETSAL e a Biblioteca Escolar Maria Zélia Teixeira Cavalcante. Para tanto, recorremos ao Projeto Político Pedagógico da ETSAL e identificamos que a primeira versão do mesmo foi realizada no ano de 2003, com atualizações anuais, sendo a mais recente em 2014. O planejamento educacional tem por base a visão coletiva da realidade vivida e com metas voltadas para a formação profissional técnica em educação permanente aos trabalhadores da saúde inseridos no Sistema Único de Saúde - SUS em Alagoas, de forma local e regional.

O documento está organizado em marcos conceitual, situacional e operativo. Conceitualmente descreve-se a concepção do homem, sociedade, educação, ensino e 
aprendizagem. A proposta situacional analisa as demandas sociais e científicas no setor da saúde. Já o marco operativo se divide em três: pedagógico, administrativo e comunitário.

Neste sentido, a Biblioteca Escolar Maria Zélia Teixeira Cavalcante está inserida no marco operativo na dimensão administrativa. No entanto, as ações administrativas estão voltadas meramente para a limpeza do espaço físico e não figuram ações no planejamento pedagógico de modo a incluir a biblioteca como recurso didático-pedagógico.

A análise mostrou que não foi somente uma questão de autonomia financeira, mas a atuação da biblioteca no contexto pedagógico não teve a devida participação ativa na construção do currículo escolar e tão pouco no seu papel pedagógico. A exemplo disto, temos o caso do Curso de Auxiliar de Enfermagem que, ofertado em 2010 pela ETSAL contou comum total de 2.264 alunos inscritos, com evasão 174 (outubro de 2010 a dezembro de 2014) e não desenvolveu nenhuma atividade ou serviço especializado em parceria com a biblioteca.

O curso apresenta carga horária de 700 horas, sendo 500 horas de concentração
(teoria) e 200 horas de dispersão (estágio), tendo como meta oferecer a
complementação do Curso de Técnico de Enfermagem para os alunos que
participaram do Curso de Auxiliar de Enfermagem, pelo PROFAE, inseridos no SUS
e como objetivos específicos qualificar esse profissional de Enfermagem, melhorando
a assistência á saúde da população e contribuir com o crescimento social e profissional
dos trabalhadores dessa categoria. (COSTA, 2016, p. 13)

Observamos um curso que possui 500 horas de concentração (teoria) deveria necessariamente incluir a biblioteca no processo de ensino-aprendizagem. Segundo Bordenave e Pereira (2002, p. 261) a "[...estrutura da biblioteca e da organização dos materiais bibliográficos, parece demonstrar a conveniência de oferecer aos alunos - ao começar o ensino de cada disciplina - uma orientação sobre a localização e disponibilidade de materiais bibliográficos...]". Algumas ações no âmbito pedagógico influenciam diretamente no desenvolvimento das atividades da biblioteca, por ser um recurso didático-pedagógico que auxilia na pesquisa de trabalhos produzidos em sala de aula e na construção do conhecimento através do auxílio de levantamento bibliográfico. Percebemos que essa Biblioteca não cumpriu seus objetivos pedagógicos, pois conforme Campello (2009, p. 42) afirma:

[...] maior envolvimento ocorre quando orienta os alunos na utilização de fontes de informação, mostrando possibilidades de acesso e explicando detalhes sobre seu uso; ensinando-lhes, por exemplo a utilizar índices de enciclopédias e almanaques às vezes, orienta também na elaboração de trabalho escrito, no que diz respeito à apresentação e a normalização.

Os setores envolvidos com a Biblioteca devem ficar atentos quanto a sua importância no processo de ensino-aprendizagem, a falta de interação pode causar o comprometimento do 
A biblioteca escolar Enfermeira Zélia Maria Teixeira Cavalcante e a educação permanente em saúde: recurso didático-pedagógico

trabalho em equipe na prestação serviços a sua comunidade escolar. Diante disso Perucchi (1999, p. 80) afirma que:

A biblioteca escolar deve ter papel de destaque no processo educativo, devido às várias informações e materiais que pode oferecer. É objetivo da biblioteca, servir diretamente às escolas ou instituições de ensino com o mesmo rigor das bibliotecas especializadas.

De acordo com alguns autores a biblioteca é por excelência o lugar de acesso ao conhecimento através de diversos suportes informacionais como os livros, periódicos, acervos virtuais, entre outros, neste sentido se faz necessário inserir na construção do currículo escolar que articula o ensino, pesquisa e extensão no processo de ensino/aprendizagem, onde o Bibliotecário deve ser o facilitador.

Na estrutura e organização curricular, devem ser consideradas as formas de aprender do
educando adulto, seus esquemas de assimilação, conhecimentos e experiências prévios,
determinantes histórico-sociais e influências dos padrões culturais no processo de
ensino-aprendizagem. A organização curricular está estruturada em módulos na
concepção do princípio da integralidade, na articulação teoria e prática e na integração
ensino-serviço [...]. (ALAGOAS, 2013, p. 34)

O Currículo Integrado (mapas conceituais) aplicado na ETSAL é trabalhado de forma a articular o ensino e o trabalho, teoria e prática e comunidade, possibilitando criar condições pedagógicas para que o aluno possa construir ativamente o seu próprio conhecimento a partir das experiências no trabalho e a realidade local em que está inserido. O processo educativo da escola tem por base a 'Pedagogia da Problematização', discutida, experimentada e eleita, pela comunidade escolar, como tecnologia educacional apropriada à concepção ideológica de aprendizagem do mundo moderno.

[...] o currículo integrado como plano pedagógico e sua correspondente organização institucional que articula dinamicamente trabalho e ensino, teoria e prática, ensino e comunidade. As relações entre trabalho e ensino, entre os problemas e suas hipóteses de solução devem ter sempre, como pano de fundo, as características socioculturais do meio em que este processo se desenvolve (DAVINI, 1983, p. 284).

O Mapa Conceitual do Curso de Vigilância em Saúde foi organizado por Eixos Temáticos (I: Organização e gestão do processo de trabalho da vigilância em saúde no âmbito da atenção básica, 2: Execução de ações e procedimentos técnico-operacionais, 3 - Educação e Comunicação). Observamos a Área I e suas Unidades Integradoras.

Cada unidade de ensino tem um tema a ser desenvolvido, o conteúdo é explicado com base no "Estudo de Caso" e textos complementares. O Estudo de Caso é um método de pesquisa que consiste em aprofundar o conhecimento em uma unidade individual ou grupal e deve entender a forma e os motivos que levaram a determinada decisão, as áreas são estudadas de 
forma individual. Percebe-se que estes referenciais não remetem a outras fontes de pesquisas científicas de forma mais aprofundadas porque os materiais didáticos foram construídos e usados como fontes principais de informações, mesmo que no período de concentração das aulas teóricas dos alunos em sala de aula tenham ocorrido atividades de discussões, leitura de textos, exibições de vídeos e vivências no campo onde irão atuar ou já atuam.

Caso haja alguma dúvida é que o instrutor sugere uma pesquisa mais aprofundada sobre a temática estudada, mas observamos que não havia um direcionamento de pesquisas de cunho científico para o uso da biblioteca escolar. Os módulos dos cursos não indicam referências bibliográficas com base nas Unidades de Ensino, mediante o conteúdo temático, que é um objeto documental (um referencial bibliográfico) do acervo físico, virtual ou misto. Compreende-se que:

[...] os recursos pedagógicos de que dispõe como meios e não sns em si mesmos, possibilitando aos estudantes o desenvolvimento de competências que esteja em sintonia com a realidade que irão enfrentar no mundo do trabalho, que se caracteriza, no inicio do século XXI, por sua mobilidade e escassez de empregos, pelo aumento de exigências na qualificação da mão-de-obra, pela perda da estabilidade e dos contratos de trabalho por tempo indeterminado, repassando ao trabalhador a responsabilidade de gerenciar sua carreira a fim de produzir melhor e sobreviver dentro das organizações (GOMES; MARINS, 2004, p. 27).

Na discussão de Fiscarelli (2007, p. 1) sobre material didático e prática docente é trazido à baila a seguinte reflexão:

[...] pensar um pouco mais sobre esses materiais no cotidiano escolar; na maneira como os professores concebem esses materiais e apropriam-se deles em sua prática docente; nas implicações que surgem ao introduzir-se materiais no ensino e nas maneiras e possibilidades de preparar os professores para essas implicações. Fazer uso de um material em sala de aula, de forma a tornar o processo de ensino aprendizagem mais concreto, menos verbalístico, mais eficaz e eficiente, é uma preocupação que tem acompanhado a educação brasileira ao longo de sua história. Historicamente, o uso de materiais diversificados nas salas de aula, alicerçado por um discurso de reforma educacional, passou a ser sinônimo de renovação pedagógica, progresso e mudança, criando uma expectativa quanto à prática docente, já que os professores ganharam o papel de efetivadores da utilização desses materiais, de maneira a conseguir bons resultados na aprendizagem de seus alunos.

Dentro dessa perspectiva foi realizado o processo de leitura em todos os Planos de Cursos e Materiais Didáticos (conteúdos), que resultou em uma lista de indicações bibliográficas, para que os coordenadores pedagógicos dos cursos avaliassem. O objetivo desse trabalho foi promover um diálogo de modo a inserir a biblioteca no Projeto Político Pedagógico como mais um recurso didático. A lista sugerida para a aquisição foi de 200 títulos, nas áreas de vigilância sanitária, epidemiologia, radiologia, anatomia humana, hematologia, doenças 
A biblioteca escolar Enfermeira Zélia Maria Teixeira Cavalcante e a educação permanente em saúde: recurso didático-pedagógico

endêmicas, imunização, saúde pública, enfermagem, política do SUS, educação permanente, entre outros.

O bibliotecário pode atuar de forma ativa e proativa colaborando com sugestões, tendo por base a visão integrada ao currículo, adaptação do universo do ensino tradicional da matriz curricular por disciplina e o estudo do conteúdo programático para as indicações bibliográficas. Além dos referenciais que constituem os acervos físicos, é necessário destacar as pesquisas virtuais que podem ser feitas nos sítios da como a Biblioteca Virtual em Saúde-BVS (Ministério da Saúde, Fiocruz, Saúde Pública, BVS Brasil, Scielo, BVS Enfermagem, Portal Regional BVS, Portal de Revistas Científicas em Ciências da Saúde), entre outros.

A Biblioteca Virtual em Educação Profissional em Saúde (BVS/EPS) permite o acesso online a coleções de fontes de informações que incluem trabalhos completos publicados em Anais de Congressos, livros e revistas acadêmicas, teses e dissertações, cartilhas, cadernos e livros sobre a memória e as experiências educacionais das ET-SUS. O controle do material bibliográfico em Educação Permanente em Saúde deve seguir os procedimentos e formas de organização das informações de determinadas áreas de coleta, seleção de documentos, formas de registros das informações e indexação; englobando a administração da base de dados, alimentando e validando os registros, de novas fontes de informações, como suportes tecnológicos e metodológicos.

Atualmente, as 40 instituições denominadas Escolas Técnicas do SUS, Centros Formadores de Recursos Humanos ou Escolas de Saúde Pública do SUS estão presentes em todos os estados brasileiros. São instituições que além da qualificação profissional dos trabalhadores de nível médio na saúde, buscam uma formação que considera a relevância das relações sociais em que esses alunos estão inseridos, com destaque para o cotidiano de trabalho, as relações com os demais membros da equipe, construindo junto com o aluno uma reflexão aonde o processo de trabalho vai além da prática específica. Formam uma Rede de Escolas Técnicas do Sistema Único de Saúde - RET-SUS, em sua maioria lotada nas Secretarias Estaduais de Saúde, através da Portaria $n^{\circ} 1.298$ de 28 de novembro de 2000 e atualizada pela Portaria $n^{\circ} 2.970$ de 25 de novembro de 2009. (COSTA, 2016, p. 42).

Essa parceria possibilita a integração entre as bibliotecas da rede e compartilhamento de fontes de informações científicas e técnicas relevantes, com temáticas que podem fortalecer a Biblioteca Escolar Maria Zélia Teixeira Cavalcante. Vale destacar que tal biblioteca teve sua primeira participação no VI Encontro da Biblioteca Virtual em Educação Profissional em Saúde (BVS/EPS), em julho de 2018, o que pode ser considerado como um passo importante para que a biblioteca se torne mais ativa e integrada, possibilitando a interação entre biblioteca e o processo de ensino aprendizagem. 
Com a integração da ETSAL a RET-SUS percebemos mudanças significativas nos setores e serviços envolvidos na oferta de cursos próprios pois, houve a necessidade de adaptação exigidas pelo novo contexto institucional. Foi possível perceber como pontos positivos a criação de um novo perfil de educação para profissionalização, educação permanente, aperfeiçoamento docente e a renovação das políticas pedagógicas. Já os pontos negativos estão relacionados a falta de estrutura adequada para a Biblioteca Escolar Maria Zélia Teixeira Cavalcante e a inexistência de oferta de apoio pedagógico com materiais adequados tendo somente, reduzindo a biblioteca a uma função meramente administrativa.

\section{Considerações finais}

A Biblioteca Escolar Maria Zélia Teixeira Cavalcante inserida ativamente nas atividades desenvolvidas pela Escola Técnica de Saúde Professora Valéria Hora pode contribuir sobremaneira para consolidar a educação profissionalizante nas modalidades de ensino técnico multiprofissional (formação profissional técnica de nível médio e educação permanente) e fortalecer o exercício profissional no contexto da saúde tendo por base os princípios e diretrizes postulados pelo Sistema Único de Saúde (SUS).

Ao longo de nosso estudo foi possível identificar que os serviços ofertados pela biblioteca foram deficientes, talvez pelo fato da mesma não constar no Projeto Político Pedagógico e não ter sido inserida no currículo escolar durante a transição pedagógica quando os cursos para a comunidade deixaram de ser ofertados centralizadamente e passaram a ser descentralizados e a metodologia tradicional passou para metodologia ativa de aprendizagem com a prática de ensino por problematização e estudo de caso.

Entendemos que sua participação pedagógica deveria ter sido feita na análise do material instrucional (instrutor) e material didático (aluno). O uso de pesquisa escolar na biblioteca pode e deve ser uma fonte a mais de pesquisa na prática de ensino-aprendizagem em sala de aula (período de concentração). Além disto, observarmos que o acervo é deficitário, inexistem recursos tecnológicos e infraestrutura adequada, a frequência de usuários esporádica e, ainda, não possui bibliotecário. Entendemos que no âmbito dos cursos descentralizados é necessário trabalhar também com a Biblioteca Virtual em Educação Permanente em Saúde e a inclusão de um referencial bibliográfico que remeta ao acervo físico, virtual ou misto para atender as demandas informacionais dos cursos na prática de ensino-aprendizagem em sala de aula. 
A biblioteca escolar Enfermeira Zélia Maria Teixeira Cavalcante e a educação permanente em saúde: recurso didático-pedagógico

É recomendável que os materiais utilizados pelos instrutores e pelos alunos utilizem fontes de pesquisas científicas com critérios de qualidade nos campos de integração ensinotrabalho-comunidade, tornando a Biblioteca Escolar Enfermeira Zélia Maria Teixeira Cavalcante mais uma ferramenta pedagógica importante na aquisição e disseminação da informação. E tudo isto só será possível com um novo olhar por parte da gestão e a possibilidade de contratação de um bibliotecário que envide esforços para transformar a realidade atual da biblioteca estudada.

O trabalho de conscientização dos gestores e a busca por parceria com os coordenadores pedagógicos será essencial para o entendimento da importância de se inserir a biblioteca no projeto Político Pedagógico e no processo didático de acordo com a realidade escolar. A atuação do bibliotecário é essencial no acesso às fontes de informações científicas e técnicas relevantes, bem como na articulação de parcerias com outras instituições envolvidas com as temáticas da área da saúde. O trabalho do bibliotecário também será decisivo na mediação da informação entre alunos e professores (instrutores) e no auxílio as pesquisas dos conteúdos programáticos em sala de aula e no incentivo do uso do acervo físico ou virtual para o fortalecimento da prática assistencial e da produção científica de qualidade na área da saúde no estado de Alagoas.

\section{Referências}

ALAGOAS. Conselho Estadual de Educação. Câmara de Educação Profissional. Resolução no 029/2016-CEE-AL. Dispõe sobre a regulamentação da oferta de cursos e programas de educação profissional e tecnológica, no Sistema Estadual de Ensino do Estado de Alagoas. Diário Oficial [do] Estado de Alagoas (DOEAL), 26 de janeiro de 2017, p. 75. Disponível em: https://www.jusbrasil.com.br/diarios/134446556/doeal-poder-executivo-17-01-2017-pg79. Acesso em: 09 maio 2017.

ALAGOAS. Universidade Estadual de Ciências da Saúde. Escola Técnica de Saúde Prof ${ }^{a}$. Valéria Hora - ETSAL. Plano de curso: curso técnico radiologia. Maceió, 2013. Disponível em: https://concursopublico.uncisal.edu.br/files/11/Plano\%20de\%20Curso\%20\%20T\%C3\%A9cnico\%20em\%20Radiologia.pdf. Acesso em: 03 jan. 2019.

ANDRADE, Eugênia Albino. A biblioteca faz a diferença. In: CAMPELLO, Bernadete Santos (org.). A biblioteca escolar: temas para uma prática pedagógica. Belo Horizonte: Autêntica, 2002.

BORDENAVE, Juan Díaz; PEREIRA, Adair Martins. Estratégias de ensino-aprendizagem. 24. ed. Rio de Janeiro: Vozes, 2002. 
BRASIL. Constituição Federal de 1988. Promulgada em 5 de outubro de 1988. Disponível em: http://www.planalto.gov.br/ccivil_03/constituicao/constituição.htm. Acesso em: 16 set. 2018.

BRASIL. Ministério da Saúde. Secretaria de Gestão do Trabalho e da Educação na Saúde. Departamento de Gestão da Educação na Saúde. Projeto de Profissionalização dos Trabalhadores da Área de Enfermagem. Profissionalização de auxiliares de enfermagem: cadernos do aluno: saúde da mulher, da criança e do adolescente. Brasília: Ministério da Saúde; Rio de Janeiro: Fiocruz, 2003. 160p.

Disponível em: http://bvsms.saude.gov.br/bvs/publicacoes/profae/pae_cad8.pdf. Acesso em: 19 set. 2018.

BRASIL. Lei n. 12.244, de 24 de maio de 2010. Dispõe sobre a universalização das bibliotecas nas instituições de ensino do País. Brasília, 2010.

CAMPELlO, Bernadete Santos (org.). A biblioteca escolar: temas para uma prática pedagógica. Belo Horizonte: Autêntica, 2002.

CAMPELLO, Bernadete Santos. Letramento informacional: função educativa do bibliotecário na escola. Rio de janeiro: Autêntica, 2009.

CÔRTE, Adelaide Ramos e; BANDEIRA, Suelena Pinto. Biblioteca escolar. Brasília: Briquet de Lemos, 2011.

COSTA, Leila Cristina Fernandes. Percursos ocupacionais e evasão no curso técnico de enfermagem na Escola Técnica de Saúde Professora Valéria Hora - ETSAL. 2016. 95 f. Dissertação (Mestrado Profissional em Educação Profissional em Saúde) - Fundação Oswaldo Cruz. Escola Politécnica de Saúde Joaquim Venâncio, Rio de Janeiro, 2016.

FISCARELLI, Rosilene Batista de Oliveira. Material didático e prática docente. Revista Ibero Americana de Estudos na Educação, Araraquara, v. 2, n. 1, 2007. Disponível em: http://seer.fclar.unesp.br/iberoamericana/article/view/454. Acesso em: 09 jun. 2018.

GOMES, Heloisa Maria; MARINS, Hiloko Ogihara. A ação docente na educação profissional. São Paulo: Senac, 2004.

MACIEL, Alba Costa; MENDONÇA, Marília Alvarenga Rocha. Bibliotecas como organizações. Rio de Janeiro: Interciência, 2000.

MARCONI, Marina de Andrade; LAKATOS, Eva Maria. Fundamentos de metodologia científica. 6. ed. São Paulo: Atlas, 2006.

MICCAS, Fernanda Luppino; BATISTA, Sylvia Helena Souza da Silva. Educação permanente em saúde: metassíntese. Revista de Saúde Pública, São Paulo, v. 48, n. 1, p. 170-185, Feb. 2014.

MORO, Eliane Lourdes da Silva (org.) et al. Contextos formativos e operacionais das bibliotecas escolares e públicas brasileiras. Brasília: Conselho Federal de Biblioteconomia, 2015. 
A biblioteca escolar Enfermeira Zélia Maria Teixeira Cavalcante e a educação permanente em saúde: recurso didático-pedagógico

MOTA, Francisca Rosaline Leite. Bibliotecários e professores no contex to escolar: uma interação possível e necessária. In: SEMINÁRIO BIBLIOTECA ESCOLAR: ESPAÇO DE AÇÃO PEDAGÓGICA, 3.,2004. Belo Horizonte. Anais eletrônicos... Belo Horizonte: UFMG, 2004. Disponível em: http://gebe.eci.ufmg.br/downloads/321.pdf. Acesso em: 12 jan. 2020 .

PERUCCHI, Valmira. A importância da biblioteca nas escolas públicas municipais de Criciúma - Santa Catarina. Revista ACB: Biblioteconomia em Santa Catarina, Florianópolis, v. 4, n. 4, 1999. Disponível em: https://revista.acbsc.org.br/racb/article/view/341. Acesso em: 24 abr. 2017.

DAVINI, Maria Cristina. Currículo integrado. CADRHU: Texto de apoio/Unidade 2, p. 282289. Adaptação e resumo por José Paranaguá de Santana para a Capacitação Pedagógica do programa de formação de pessoal de nível médio em saúde (Projeto Larga Escala). OPAS, Brasília, 1983. Disponível em:

http://lagarto.ufs.br/uploads/content_attach/path/11340/curriculo_integrado_0.pdf. Acesso em: 09 maio 2017.

SEVERINO, Antônio Joaquim. Metodologia do trabalho científico. 23. ed. São Paulo: Cortez, 2007.

SILVA, Eduardo Valadares da; MORAES, Fabiano de Oliveira. Biblioteca escolar como espaço de reinvenções curriculares. In: CONGRESSO BRASILEIRO DE BIBLIOTECONOMIA, DOCUMENTAÇÃO E CIÊNCIA DA INFORMAÇÃO, 25., 2013, Florianópolis. Anais eletrônicos... Florianópolis: FEBAB, 2013. Disponível em: https://portal.febab.org.br/anais/article/view/1242. Acesso em: 08 set. 2018.

SILVA, Elias Barbosa da. Acesso e universalização da biblioteca escolar como condição de qualidade na educação básica. 2020. 233 f. Dissertação (Mestrado em Educação) Universidade Federal do Paraná, Curitiba, 2020.

Artigo submetido em: 13 set. 2019

Artigo aceito em: 06 out. 2020 